\title{
能源富集区市域经济发展水平空间格局演变 基于晋陕蒙甘宁地区
}

\author{
李 博 ${ }^{1,2}$, 张文忠 ${ }^{2,3}$, 余建辉 2,3 , 刘倩倩 4,5 \\ (1. 天津理工大学管理学院, 天津 $300384 ; 2$. 中国科学院地理科学与资源研究所, 区域可持续发展与模拟重 \\ 点实验室, 北京 $100101 ; 3$. 中国科学院大学, 北京 100049 ; 4 . 南京师范大学地理科学学院, 南京 210023; \\ 5. 江苏省地理信息资源开发与利用协同创新中心 , 南京 210023)
}

\begin{abstract}
摘要：采用熵权 TOPSIS 法对我国晋陕蒙甘宁这一典型能源富集区各地级以上城市的市域经 济发展水平进行综合评价, 进而使用马尔可夫转移概率分析方法和 ESDA 空间分析方法, 探索 该地区市域经济发展水平时空分异格局的演化特征, 结果显示: (1)该地区的市域经济发展差 距在波动中下降; (2)各等级城市在不同时期演化规律截然相反,随时间推移,除低等级之外的 各等级城市均表现出较高的等级下降风险; (3)该地区城市的市域经济水平曾存在一定空间负 相关, 到 2015 年这种关系则不再显著; (4)该地区呈现以局部为核心区的格局, 但西部地区明显 趋冷; (5)市域经济系统整体处于耦合协调度较低的状态,发展不平衡、不协调的问题较突出。
\end{abstract}

关键词：晋陕蒙甘宁地区; 市域经济; 经济发展水平; 熵权 TOPSIS 方法;ESDA

能源富集区是一类特殊的资源型区域，能源型产业占据其主导地位，资源型经济特 色突出 ${ }^{[1]}$ ，一般采用高投人、高耗能的粗放型发展模式 ${ }^{[2]}$ 。晋陕蒙甘宁地区是位于我国中 西部的重点受关注区域，主要包括五个省区，分别是山西省、陕西省、内蒙古自治区， 甘肃省和宁夏回族自治区。晋陕蒙甘宁地区也是我国西部大开发战略的关键区域，这一 地区的能源资源较为富集，煤化工产业布局相对密集，是我国中西部典型的能源富集 区。首先, 内蒙古、山西、陕西、宁夏四省区能源资源集中, 尤以煤炭资源最为突出, 煤炭储量一度占全国总量近 $67 \%$ [1] 。其中, 山西省除省会太原外, 其余 10 个地级市均为 资源型城市 ${ }^{[3]}$, 具有煤炭储量大、品种齐全、埋层浅、易开采等特点, 累计探明储量在 2661 亿 $\mathrm{t}$ 以上; 内蒙古自治区累计探明的煤炭资源保有储量为 2317.1 亿 $\mathrm{t}$, 占全国保有储 量的 $22 \%$, 潜力巨大; 宁夏回族自治区煤炭资源品种多、质量好, 煤炭保有资源储量约 303 亿 $\mathrm{t}$, 预测资源量 1055 亿多 $\mathrm{t}^{[4]}$; 陕西省能源资源丰富, 含煤面积占全省面积的四分之 一，原煤、原油、天然气储量均位居全国前列 [5]。其次，甘肃省依托丰富的能源资源和矿 产资源, 境内有长庆、玉门两大油田 ${ }^{[6]}$, 陇东作为甘肃省主要的石油化工基地, 石油资源 储量为 28.47 亿 $\mathrm{t}$, 煤炭预测储量为 1342 亿 $\mathrm{t}^{[7]}$, 是我国能源版图的重要组成部分。因此, 在 “十二五” 规划中，我国就明确了在晋陕蒙甘宁地区重点建设山西、鄂尔多斯盆地、

收稿日期：2019-01-10; 修订日期：2019-05-15

基金项目：国家自然科学基金项目（41230632，71403290，41671166); 美丽中国生态文明建设科技工程专项 (XDA23100302)

作者简介: 李博 (1981- ), 男, 天津人, 博士, 副教授, 硕士生导师, 主要从事区域经济、城市发展、资源环境经 济与经济地理研究。E-mail: mg2011818@126.com

通讯作者: 刘倩倩 (1990-), 女, 河南开封人, 博士, 讲师, 主要从事城市地理研究。

E-mail: liuqq.15b@igsnrr.ac.cn 
内蒙古东部地区等国家综合能源基地 ${ }^{[8]}$; 同时，陕西省榆林地区、宁夏宁东能源化工基地 以及陕甘宁油气田开发也被列入国家规划 ${ }^{[1]}$ 。由此可见，晋陕蒙甘宁地区无疑是具有代表 性的典型能源富集区。受资源和地理位置等因素的制约，晋陕蒙甘宁地区各省份的经济 发展也存在明显区域差异，同时这种差异也反映出该地区在经济发展方面的空间结构与 布局特征。现阶段我国火电行业 $96 \%$ 以上的发电量来自煤电 ${ }^{[10]}$, 作为世界最大的煤炭消

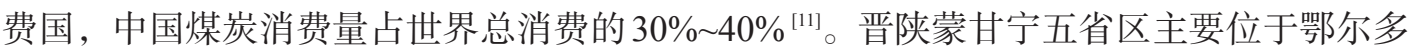
斯盆地和沈水盆地，该地理特征为其提供了以煤炭和天然气为代表的丰富矿产资源，也 奠定了该地区作为我国煤炭主产区的重要地位。尽管作为中国重要的能源安全基地和能 源化工基地，晋陕蒙甘宁地区具有重要的战略意义，但从空间结构上看，该地区横跨我 国中西部区域，其中位于区域核心位置的西安市经济发展水平一枝独秀，但其对周边城 市的辐射带动能力较为有限, 特别是对西北部和东北部较远距离城市而言, 影响作用相 对较弱。该地区由于东南部毗邻我国北方经济发展最为成熟的京津冀地区，因此其较多 临近城市受到京津冀的辐射带动而经济发展状况较好, 但主要仍以能源化工基地、能源 基地和通道的功能为主, 经济驱动引擎较为单一, 具有一定的脆弱性。西南部地区则由 于缺乏较强的经济热点区带动, 经济发展水平明显较为落后。整体上看, 晋陕蒙甘宁地 区除西安、太原、呼和浩特、兰州、银川五座省会城市以及鄂尔多斯、榆林、包头等典 型资源型城市的经济发展水平相对突出外, 其他多数城市往往在区域乃至全国处于经济 发展较为落后的位置, 城市发展水平分化情况较为严重, 可以说该地区整体上属于经济 发展相对落后的地区。

但是，作为我国重要的能源富集区，防范能源类资源型城市在发展中可能面临的重 大风险以及摆脱发展中面临的困境，显然对该地区的经济持续健康发展具有重要意义。 当今区域经济协调一体化发展越来越成为城市之间竞争和发展的重要战略和必由之路, 其中尤以市域经济的全面协调发展为重。市域经济是以城市为极核的经济，同时城市的 极化作用甚至会越出城市行政边界，在更大范围内对经济发展发挥重要的促进作用。我 国早期区域经济研究多为针对省域经济或县域经济的研究, 实际上都属于行政区域经济 研究。然而，随着县域、省域等行政区经济束缚的打破，城市作为区域经济中心的功能 和作用越来越突出 ${ }^{[12]}$ 。因此, 有关我国市域经济发展的空间差异 ${ }^{\left[{ }^{[1]}\right]}$, 以及市域经济网络 联系形成机制 ${ }^{[14]}$ 等方面的研究也应运而生。可见以城市为核心，发展晋陕蒙甘宁地区的 市域经济，以产业联动作为城市之间的联系，对我国能源富集区实现经济全面协调发展 具有重要现实意义。

近些年来，越来越多的研究者从不同角度对晋陕蒙甘宁地区的发展问题给予了关 注, 并且针对如何促进晋陕蒙甘宁地区协调一体化发展进行了探索，从总体层面 ${ }^{\left[{ }^{[15}\right.}$ 以及 省区层面 ${ }^{[16-22]}$ 进行了一系列富有成效的研究。总体而言，山西、陕西、内蒙古、甘肃和宁 夏处于中西部地区的重要地理位置, 在国民经济发展中占有重要地位。已有研究普遍认 同晋陕蒙甘宁地区经济一体化发展的重要意义, 并认为现代产业体系的建立、经济发展 的健康性与可持续性，以及产业空间和经济空间的科学布局与有效协同对有效提高该地 区经济一体化水平, 更好地发挥辐射带动性具有重要作用。因此, 应当进一步采取有效 手段从区域宏观视角，考察该地区空间维度上的协调发展现状，从而探讨如何有效发挥 区域联系优势并探索实现市域经济协调发展的有效路径。 
本文在现有研究成果的基础上以晋陕蒙甘宁地区的城市区域为空间分析对象，在运 用熵权 TOPSIS 方法的基础上，将马尔可夫转移概率矩阵、探索性空间数据分析和耦合协 调度分析相结合，对该地区的市域经济发展水平进行综合评价，并探讨其经济空间格局 的演化特征，为优化晋陕蒙甘宁的市域经济空间结构、推动城市经济协调发展提供理论 与决策参考，从而在评价能源富集区市域经济发展水平和空间格局演变，以及指导该类 地区经济的平衡与协调发展方面进行有益探索。

\section{1 研究方法与数据来源}

\section{1 熵权 TOPSIS 法}

本文利用熵权 TOPSIS 法（Technique for order preference by similarity to ideal solution）对我国晋陕蒙甘宁地区的地级以上城市经济发展水平进行综合评价。其中，TOPSIS 方法是一种多指标决策方法 ${ }^{[23]}$, 优点在于只对效用函数的单调增（减）性做出要求, 但其局限性在于，当使用传统 TOPSIS 方法时，往往采用具有一定主观性的赋权方法，因 而影响了评估结果的有效性。采用基于熵理论进行赋权的熵权 TOPSIS 方法则可以有效解 决这个问题，因此越来越多的研究开始使用这种方法来评估和分析区域发展问题 ${ }^{[24,25]}$ 。本 文使用该方法的目的在于其是一种较为客观的方法, 能够对晋陕蒙甘宁地区市域经济的 各子系统与总体发展水平进行较为综合的评价。

\section{2 马尔可夫链}

在概率论和相关领域中，马尔可夫链表示的是从一个“状态”（一种情况或一组值） 跨越到另一个状态的数学系统。马尔可夫链可以根据给出的状态空间计算从一个状态到 另一个状态的跳跃或过渡的概率, 通俗点讲就是一个过程如果只能基于目前的状态来预 测未来, 且根本不需要历史数据, 则该过程就可称为满足马尔可夫属性。该方法的优点 在于其是一种具有离散时间和状态的马尔可夫过程，也是揭示不同区域间所研究对象指 标的相对位置变化过程及这种变化可能性的有效工具。其局限性是需要通过恰当的状态 划分使各种状态的初始概率条件得到满足 ${ }^{[2]}$ 。本文使用该方法的目的在于, 通过对晋陕 蒙甘宁地区各城市的连续市域经济发展水平指数进行离散化处理, 将其划分为有限类型 并计算相应类型的概率分布和不同年份的变化，从而近似描绘各城市的市域经济发展变 化的全过程。如果一个城市的经济发展处于一定的状态水平, 并且经岁月变迁后在一定 年限内保持不变, 则这类转移将是稳定的; 如果市域经济发展水平提高, 则其市域经济 发展水平的等级转移可以被认为是上升的，反之可以被认为是下降的。

\section{3 探索性空间数据分析}

探索性空间数据分析（ESDA）着重于通过描述性和可视化的空间分布技术，识别 与区分地理数据特征，进而观察非典型的位置，从中发现空间关联、聚类或热点区模 式。ESDA 是用来测量自然或者社会经济现象空间相关性的有效方法，全局空间自相关 和局部空间自相关是其中两项重要内容, 常用指标有 Global Moran's $I$ 、Local Moran's $I$ 、 Getis-Ord General $G$ 和 Getis-Ord $G^{*}$ 等等。ESDA方法侧重于描述性方法而非正式的假设 检验。并需要在地图上链接数字和图形程序, 以帮助检测数据中的空间模式, 基于数据 的地理位置做出假设和评估空间模型。该方法的优点在于其重点关注的是空间数据的性 质与模式, 以及异常值的分布位置等, 具有一定的交互性与迭代性。其局限性在于, 尽 
管其适合于可视化研究与空间模式的探索, 但传统 ESDA 方法对所发现的空间模式解释 不足 ${ }^{[27]}$, 因此往往需要与其他解释性分析工具相结合。本文使用该方法的目的在于其能 够更为深人地探索与刻画晋陕蒙甘宁地区市域经济发展的空间关联性与空间集聚格局的 演化特征。事实上，通过探索性空间数据分析和熵权 TOPSIS 方法相结合来分析区域经济 发展的时空演化特征，已成为学术界越来越接受的研究模式之一 ${ }^{[28-30]}$ 。

\section{4 耦合协调度测算与分析}

耦合协调度测算分析方法主要是通过构造耦合度函数和耦合协调度函数来评价两个 或多个系统之间相互作用的耦合兼容性, 目前已广泛应用于许多领域。耦合协调度测算 首先需要计算耦合度，耦合度指标反映的是每个子系统的耦合状态，就是系统彼此之间 交互作用的影响程度。通过参考和推广物理学中有关容量耦合和容量耦合系数模型的概 念 ${ }^{[31]}$, 当耦合度测算结果越小时, 表明各子系统之间越接近于无相关性的无序发展状 态，而耦合度测算结果越大时，则表明各子系统之间越接近于良性共振耦合的有序发展 状态。耦合度的优点在于能够量化反映子系统之间的兼容度，但其也存在一定的局限 性，即由于耦合程度只是反映系统之间或元素之间的协同程度，往往只有强弱之分，而 无良莠分别, 因此仅依靠耦合度指数的测算, 会导致在某些情况下出现判断失准。例 如, 当子系统的水平值都相对较弱时, 也有可能获得更高的耦合评估结果 ${ }^{[2]}$ 。因此需要 在计算耦合度基础上进一步测量耦合协调度来衡量系统间相互作用的良性耦合程度和协 调状态好坏 ${ }^{[33]}$ 。耦合协调模型是用来测量每个子系统的耦合协调度的工具方法 ${ }^{[34]}$ 。耦合 协调度取值范围也在 $0 \sim 1$ 之间，最大值表示系统之间处于最佳协调状态，耦合协调度得 分越小，则协调性越差。参考耦合协调度的相关研究，可以得到设定耦合协调度的 10 个 等级 ${ }^{[35]}$ 。本文使用该方法的目的在于，能够通过量化手段考察晋陕蒙甘宁地区市域经济 发展中各子系统之间的耦合协调状态，从而对发展不协调不平衡的城市加以识别。

\section{5 数据来源与指标体系构建}

本文将研究区内 47 个地级以上城市作为基本单元，主要对其城市空间结构特征进行 研究。社会经济指标数据主要来源于 2006 年、2011 年和 2016 年的《中国城市统计年 鉴》。相关年份的《中国统计年鉴》和有关城市的国民经济和社会发展统计公报等; 此 外，还使用了来自全国 1：400 万基础地理信息数据库的图形数据。根据指标体系选取的 综合性、代表性与可行性原则, 并参考已有研究, 主要从经济规模、经济效益、结构水 平、人民生活，以及对外开放五个方面 ${ }^{[28,30}$ 选取 21 个指标，构建晋陕蒙甘宁地区经济发 展水平评价指标体系（表 1 )。

\section{2 结果分析}

\section{1 晋陕蒙甘宁地区市域经济发展水平评价}

\subsection{1 市域经济发展水平评价与分析}

基于熵权 TOPSIS 法，针对 2005 年，2010年和 2015 年 47 个城市的 21 个指标的原始 数据进行处理, 并获得每个指标的权重（表1)。可以发现, 准则层的经济规模和经济效 益权重分别为 0.408 和 0.306 , 远高于其他方面。而在指标层面，当年实际使用外资金 额、地方财政一般预算收人和经济密度的权重分别为 $0.207 、 0.083$ 和 0.083 , 这也是权重 较高的三个指标（由于四舍五人，经济密度的实际权重略低）。上述结果表明，决定该地 
表 1 评价指标体系与权重

Table 1 Evaluation index system and weights

\begin{tabular}{|c|c|c|c|}
\hline 准则层 & 权重 & 指标层 & 权重 \\
\hline \multirow[t]{6}{*}{ 经济规模 } & 0.408 & 地区生产总值 & 0.057 \\
\hline & & 地方财政一般预算收人 & 0.083 \\
\hline & & 全社会固定资产投资总额 & 0.064 \\
\hline & & 城乡居民储蓄存款余额 & 0.064 \\
\hline & & 社会消费品零售总额 & 0.077 \\
\hline & & 邮电业务总量 & 0.062 \\
\hline \multirow[t]{5}{*}{ 经济效益 } & 0.306 & 人均地区生产总值 & 0.043 \\
\hline & & 经济密度(单位面积地区生产总值) & 0.083 \\
\hline & & 人均地方财政一般预算收人 & 0.077 \\
\hline & & 人均全社会固定资产投资 & 0.053 \\
\hline & & 人均社会消费品零售总额 & 0.050 \\
\hline \multirow[t]{4}{*}{ 结构水平 } & 0.022 & 第二产业产值比例 & 0.005 \\
\hline & & 第三产业产值比例 & 0.004 \\
\hline & & 第二产业从业人员比例 & 0.009 \\
\hline & & 第三产业从业人员比例 & 0.004 \\
\hline \multirow[t]{2}{*}{ 人民生活 } & 0.057 & 在岗职工平均工资 & 0.018 \\
\hline & & 人均城乡居民储蓄存款余额 & 0.038 \\
\hline 对外开放 & 0.207 & 当年实际使用外资金额 & 0.207 \\
\hline
\end{tabular}

区市域经济发展水平的最重要的方面是经济规模和效益，而表示对外开放程度的使用外 资水平和地方政府的财政能力是影响该地区经济发展较为重要的具体因素。

将上述指标权重与进一步计算得到的正负理想解综合起来，可以得到熵权 TOPSIS 指 数，从而来评价晋陕蒙甘宁地区的市域经济发展水平。根据每个研究年度每个城市的熵 权 TOPSIS 指数，通过对其得分进行排序，可以获得如表 2 所示的结果。从表中结果来 看，2005 年、2010年和 2015 年各市域经济发展水平的平均值（保留小数点后三位）分别 为 $0.028 、 0.060$ 和 0.120 。总体来看，表明该地区市域经济发展的总体水平有较为明显的 提升, 且平均增幅在三倍以上。

此外还应当看到，在2005-2015年，西安市、鄂尔多斯市、太原市、包头市、呼和浩 特市五座城市始终排名在前 5 位，只是位序有所变化，其中，西安市始终排名第 1 , 成为 该区域经济发展水平最高的城市，鄂尔多斯则从 2005 年的第 5 位，上升至 2010 年的第 2 位，并保持到 2015 年，表明该城市的经济发展势头迅猛。各年份全部城市评价值的变异 系数分别为 $1.174 、 1.113$ 和 1.115 , 表明在此期间, 晋陕蒙甘宁地区城市间的经济发展水 平差距在波动中有所下降，并未出现城市间经济发展水平差距不断拉大的趋势。

\subsection{2 市域经济发展水平类型划分}

为进一步比较晋陕蒙甘宁地区各市域经济发展水平的空间分布状况，运用自然断裂 点法（Natural Breaks），将2005 年、2010年和2015 年各城市经济发展水平划分为高、较 高、较低和低四个等级，并使用A $\operatorname{crcGIS} 10.2$ 软件进行基于空间的可视化表达（图 1）。

从每年位于不同层次的城市数量来看，可以发现 2005 年近 $90 \%$ 的城市处于低或较低 
表 2 摘权 TOPSIS 评价得分结果

Table 2 Results of entropy weight TOPSIS evaluation

\begin{tabular}{|c|c|c|c|c|c|c|c|}
\hline \multirow{2}{*}{ 城市 } & \multirow{2}{*}{ 省份 } & \multicolumn{2}{|c|}{ 2005年 } & \multicolumn{2}{|c|}{ 2010年 } & \multicolumn{2}{|c|}{ 2015年 } \\
\hline & & 评分 & 排序 & 评分 & 排序 & 评分 & 排序 \\
\hline 太原市 & 山西 & 0.086817 & 4 & 0.150581 & 5 & 0.310811 & 3 \\
\hline 大同市 & 山西 & 0.030331 & 10 & 0.053342 & 18 & 0.106391 & 15 \\
\hline 阳泉市 & 山西 & 0.025612 & 16 & 0.053919 & 17 & 0.107779 & 14 \\
\hline 长治市 & 山西 & 0.02716 & 12 & 0.057611 & 13 & 0.135362 & 11 \\
\hline 晋城市 & 山西 & 0.025941 & 15 & 0.069029 & 8 & 0.111182 & 13 \\
\hline 朔州市 & 山西 & 0.021891 & 20 & 0.048638 & 21 & 0.084178 & 26 \\
\hline 晋中市 & 山西 & 0.026137 & 14 & 0.051042 & 20 & 0.122687 & 12 \\
\hline 运城市 & 山西 & 0.02873 & 11 & 0.06482 & 10 & 0.095078 & 20 \\
\hline 忻州市 & 山西 & 0.013122 & 32 & 0.033217 & 30 & 0.072594 & 29 \\
\hline 临汾市 & 山西 & 0.025599 & 17 & 0.074756 & 7 & 0.102327 & 17 \\
\hline 吕梁市 & 山西 & 0.017744 & 23 & 0.060712 & 12 & 0.081633 & 27 \\
\hline 呼和浩特市 & 内蒙古 & 0.098455 & 3 & 0.198637 & 4 & 0.233922 & 5 \\
\hline 包头市 & 内蒙古 & 0.102572 & 2 & 0.237619 & 3 & 0.282427 & 4 \\
\hline 乌海市 & 内蒙古 & 0.038234 & 7 & 0.085487 & 6 & 0.190585 & 6 \\
\hline 赤峰市 & 内蒙古 & 0.017318 & 26 & 0.044762 & 25 & 0.09494 & 21 \\
\hline 通辽市 & 内蒙古 & 0.015582 & 30 & 0.042816 & 26 & 0.092771 & 22 \\
\hline 鄂尔多斯市 & 内蒙古 & 0.074129 & 5 & 0.251127 & 2 & 0.458589 & 2 \\
\hline 呼伦贝尔市 & 内蒙古 & 0.021204 & 21 & 0.047452 & 22 & 0.092247 & 23 \\
\hline 巴彦淖尔市 & 内蒙古 & 0.016145 & 28 & 0.045427 & 24 & 0.072806 & 28 \\
\hline 乌兰察布市 & 内蒙古 & 0.011993 & 33 & 0.024253 & 33 & 0.059096 & 34 \\
\hline 西安市 & 陕西 & 0.181832 & 1 & 0.327999 & 1 & 0.836099 & 1 \\
\hline 铜川市 & 陕西 & 0.010856 & 35 & 0.023898 & 34 & 0.058096 & 35 \\
\hline 宝鸡市 & 陕西 & 0.022106 & 19 & 0.045779 & 23 & 0.090395 & 24 \\
\hline 咸阳市 & 陕西 & 0.024542 & 18 & 0.055083 & 15 & 0.147474 & 10 \\
\hline 渭南市 & 陕西 & 0.017385 & 24 & 0.040796 & 27 & 0.1008 & 18 \\
\hline 延安市 & 陕西 & 0.026497 & 13 & 0.054792 & 16 & 0.10535 & 16 \\
\hline 汉中市 & 陕西 & 0.011812 & 34 & 0.024648 & 32 & 0.063477 & 31 \\
\hline 榆林市 & 陕西 & 0.015763 & 29 & 0.06406 & 11 & 0.148573 & 9 \\
\hline 安康市 & 陕西 & 0.006725 & 42 & 0.018284 & 36 & 0.046966 & 37 \\
\hline 商洛市 & 陕西 & 0.005671 & 44 & 0.017519 & 37 & 0.044247 & 39 \\
\hline 兰州市 & 甘肃 & 0.042184 & 6 & 0.068903 & 9 & 0.177503 & 7 \\
\hline 嘉峪关市 & 甘肃 & 0.036199 & 8 & 0.052576 & 19 & 0.096058 & 19 \\
\hline 金昌市 & 甘肃 & 0.017362 & 25 & 0.030953 & 31 & 0.060591 & 32 \\
\hline 白银市 & 甘肃 & 0.009191 & 36 & 0.017116 & 38 & 0.039734 & 42 \\
\hline 天水市 & 甘肃 & 0.007637 & 38 & 0.01657 & 39 & 0.045805 & 38 \\
\hline 武威市 & 甘肃 & 0.006769 & 41 & 0.012024 & 44 & 0.043758 & 40 \\
\hline 张掖市 & 甘肃 & 0.00748 & 39 & 0.013573 & 42 & 0.038761 & 44 \\
\hline 平凉市 & 甘肃 & 0.019682 & 22 & 0.015319 & 41 & 0.042247 & 41 \\
\hline 酒泉市 & 甘肃 & 0.014904 & 31 & 0.039333 & 29 & 0.084301 & 25 \\
\hline 庆阳市 & 甘肃 & 0.007473 & 40 & 0.020701 & 35 & 0.059979 & 33 \\
\hline 定西市 & 甘肃 & 0.004551 & 46 & 0.009927 & 46 & 0.029618 & 46 \\
\hline 陇南市 & 甘肃 & 0.004539 & 47 & 0.011348 & 45 & 0.038776 & 43 \\
\hline 银川市 & 宁夏 & 0.032979 & 9 & 0.055603 & 14 & 0.159866 & 8 \\
\hline 石嘴山市 & 宁夏 & 0.016908 & 27 & 0.039704 & 28 & 0.069999 & 30 \\
\hline 吴忠市 & 宁夏 & 0.008129 & 37 & 0.016087 & 40 & 0.052695 & 36 \\
\hline 固原市 & 宁夏 & 0.00466 & 45 & 0.008913 & 47 & 0.026272 & 47 \\
\hline 中卫市 & 宁夏 & 0.00611 & 43 & 0.012283 & 43 & 0.033125 & 45 \\
\hline 均值 & - & 0.027546 & - & 0.059767 & - & 0.120170 & - \\
\hline
\end{tabular}


水平，这表明大多数城市的经济水平仍有待

提高。虽然这种情况在 2010 年有所改善, 然 而到了 2015 年，更多城市水平退至低或较低 水平, 出现了更为严峻的局面。可以看出, 如何提高晋陕蒙甘宁地区城市整体经济发展 水平仍然是一项急需完成的艰巨任务。从区 域内各市域经济发展水平的空间分布来看, 高水平高层次的城市主要集中在山西、陕西 和内蒙古地区的省会城市，特别是以山西、 陕西、内蒙古的交界地区为中心，可以发现 存在一定的核心边缘空间结构特征。但随着 时间的推移，一些城市经济发展水平的退步 使该地区的市域经济空间分布特征呈现模糊 化趋势。

\section{2 晋陕蒙甘宁地区市域经济发展水平时空演化}

\subsection{1 市域经济等级变化预测}

本文利用马尔可夫链方法构造了 20052010年和 2010-2015 年的马尔可夫转移概率矩 阵，用于考察和评价该区域的市域经济发展 水平在不同层级间的变化跳跃情况，该方法 及其扩展不仅能够用来分析自然系统的变化 过程，也被很多经济地理与人文地理领域的 学者用于分析经济社会系统的变化过程。本 文认为在以 5 年为单位的一个较长时间尺度上 使用该方法具有一定的适当性 ${ }^{[2,28,30,36,37]}$, 具体 结果参见表 3 。由表中结果可知，2005-2010 年间，市域经济发展水平处于低或高的城市 都表现出了一定的上升可能。2010-2015 年 间，各城市的经济发展水平便呈现出截然不 同的趋势。除经济发展水平较低的城市外, 其他各等级的城市均表现出一定程度的等级

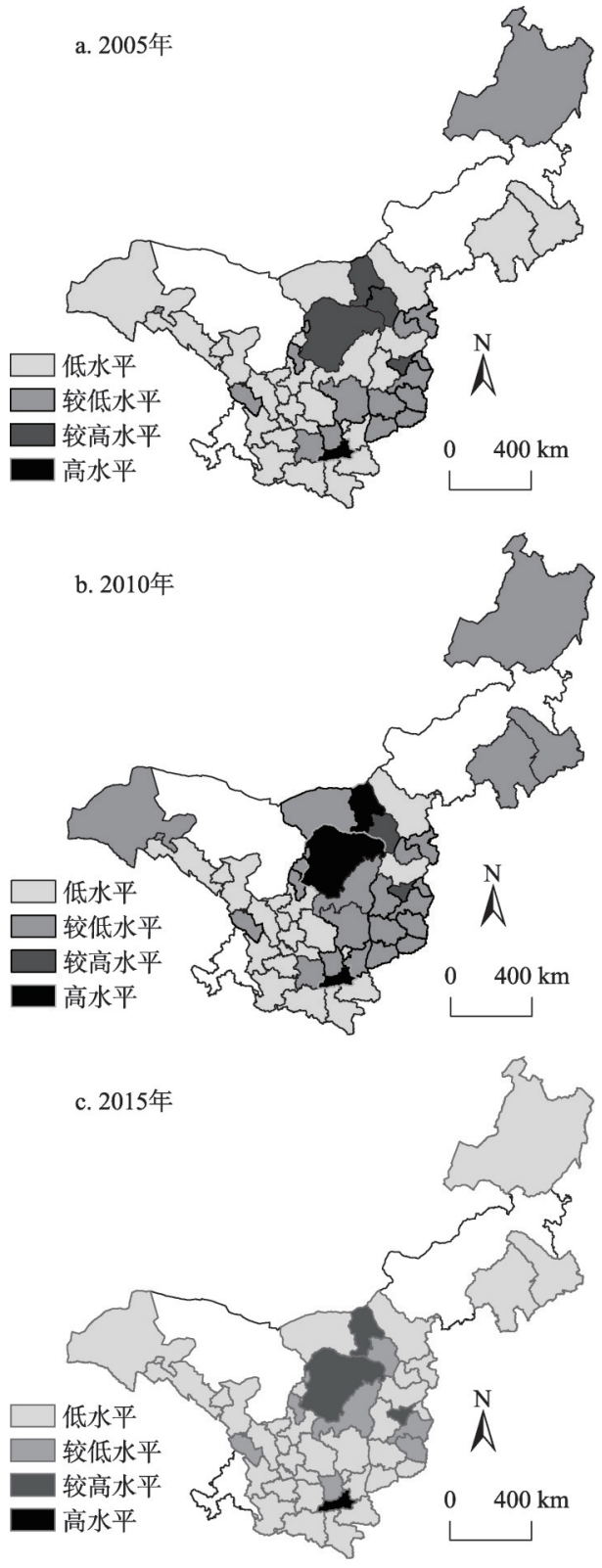

图 1 经济发展水平等级划分演化地图

Fig. 1 Evolutionary map of economic development level

表 3 马尔科夫转移概率矩阵计算结果

Table 3 Calculation results of Markov probability transition matrix

\begin{tabular}{|c|c|c|c|c|c|c|c|c|c|}
\hline \multirow{2}{*}{ 期初 } & \multicolumn{4}{|c|}{ 2005-2010年 } & \multirow{2}{*}{ 期末 } & \multicolumn{4}{|c|}{ 2010-2015 年 } \\
\hline & 低 & 较低 & 较高 & 高 & & 低 & 较低 & 较高 & 高 \\
\hline 低 & 0.692 & 0.308 & 0.000 & 0.000 & 低 & 1.000 & 0.000 & 0.000 & 0.000 \\
\hline 较低 & 0.000 & 1.000 & 0.000 & 0.000 & 较低 & 0.708 & 0.292 & 0.000 & 0.000 \\
\hline 较高 & 0.000 & 0.000 & 0.500 & 0.500 & 较高 & 0.000 & 0.500 & 0.500 & 0.000 \\
\hline 高 & 0.000 & 0.000 & 0.000 & 1.000 & 高 & 0.000 & 0.000 & 0.667 & 0.333 \\
\hline
\end{tabular}


下降可能性, 且处于低水平城市的等级改善的 可能性也较低, 高层次城市的等级下降风险则 明显增加, 市域经济发展水平出现波动的风险 更为突出。

\subsection{2 市域经济等级演化及其变化预测的空间} 格局

把 2005-2010年、2010-2015 年晋陕蒙甘宁 地区各城市的市域经济发展水平等级变化分为 上升、不变和下降。同时利用 ArcGIS 10.2 软 件对城市进行基于空间的可视化描述（图 2)。 可以发现，在 2005-2010 年间, 包头和鄂尔多 斯等 10 个城市都经历了等级上升过程, 而其 他 37 个城市则并没有经历等级上升下降的变 化; 但在 2010-2015 年间, 大同、包头、鄂尔 多斯等 20 个城市出现等级下降, 其他 27 个城 市的等级没有变化。这一结果反映出晋陕蒙甘 宁地区的市域经济发展水平等级空间格局变化 仍以陕蒙交界城市为主, 当这个中心区域的城 市等级水平提高时, 其总体水平也有所提高; 而当这个中心区域的城市等级水平下降时, 伴 随而来的则是其他城市相同的变化趋势。

\subsection{3 空间关联性的演化特征}

本文利用 ArcGIS 10.2 空间统计分析方 法，计算了 2005 年、 2010 年、 2015 年三个时 点的晋陕蒙甘宁地区市域经济发展水平全局 Moran's $I$, 结果如表 4 所示。其中, 2005 年和 2010 年的指数显著为负, 但系数的绝对值较 小，表明存在一定程度的空间负相关性，也说

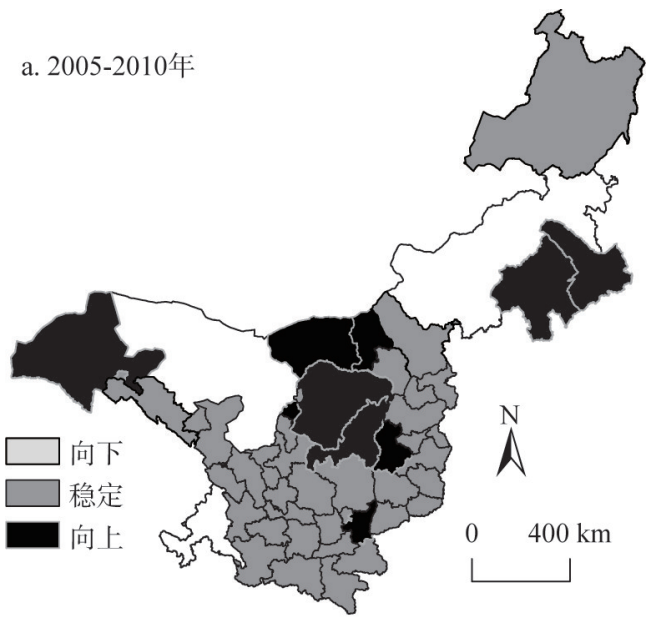

b. 2010-2015年

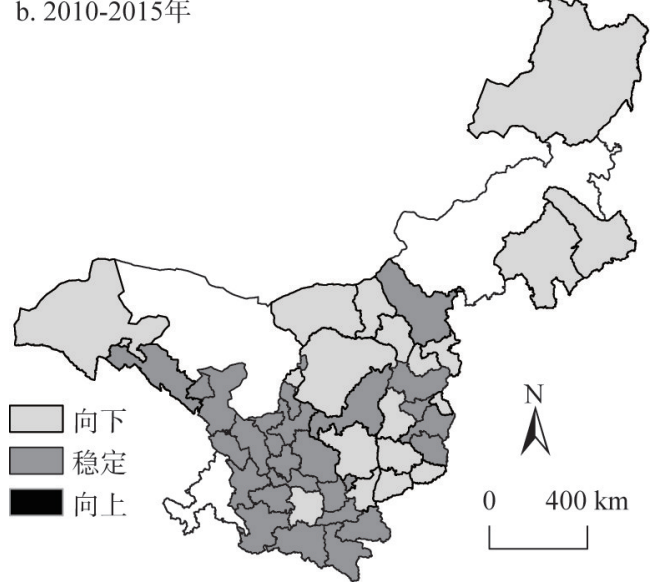

图 2 市域经济等级演化及其变化 预测的空间格局

Fig. 2 Spatial pattern of city regional economy level and its prediction 明晋陕蒙甘宁地区的市域经济发展未形成良性的正向互动关系。到 2015 年，尽管全局 Moran's $I$ 指数仍为负值，但已不再显著，表明这一非良性现象在一定程度上有所改善。

2.2 .4 冷热点区地区空间格局演化特征

为更好地认识和发现晋陕蒙甘宁地区市域经济发展水平的空间集聚格局和城市演化 特征，采用局部空间关联 Getis-Ord $G$ 指数对晋陕蒙甘宁地区市域经济发展 水平指数在 2005 年、 2010 年、 2015 年的情况进行了空间集聚格局和演化 特征分析。利用自然断点法将计算出 的各年局部空间关联 Getis-Ord $G$ 指 数进行划分, 并根据指数值大小划分 为热点区、次热点区、次冷点区和冷

\section{表 4 全局莫兰 I指数测算结果}

Table 4 Results of global Moran's $I$

\begin{tabular}{lccc}
\hline 指标 & 2005 年 & 2010 年 & 2015年 \\
\hline Moran's $I$ & $-0.0037^{*}$ & $-0.0001^{* *}$ & -0.0142 \\
$\mathrm{E}(I)$ & -0.0217 & -0.0217 & -0.0217 \\
$\mathrm{STD}(I)$ & 1.4221 & 1.7057 & 0.5927 \\
$P$ 值 & 0.0775 & 0.0440 & 0.2767 \\
\hline
\end{tabular}

注: “、“分别表示 $P<0.05 、 P<0.1$ 。 
点区四种聚集类型，其中热点区的市域经济发 展水平较高, 而冷点区的的市域经济发展水平 相对较低。利用空间可视化方法呈现上述聚合 类型（图3)，从中识别以下模式和演化特征:

首先，在本文关注的时期中，晋陕蒙甘宁 地区的市域经济发展热点区在稳定中逐步扩 大。在 2005 年, 热点区的表现是以呼和浩特 市为中心，分别重点向西延伸至临河市以及向 东延伸至大同市，形成晋蒙之间的狭长城市 群。到 2010 年和 2015 年, 热点区又以呼和浩 特为中心分别向南北方向扩展, 包括了晋蒙地 区更多的城市，有利于多个城市共同发展的良 好局面的形成。

其次，在 2005-2015 年，次热点区的空间 集聚格局并没有发生根本性变化。次热点区主 要分布在山西省和陕西省的城市地区, 以及内 蒙古中东部和甘肃省东南部的一些城市。只有 部分城市经历了热点区的转换过程。随着时间 的流逝，次热点区的空间范围逐渐缩小，并向 山西、陕西等省份的城市进行集中。同时，交 通区位优势和资源优势的重要性不断突出，使 得晋陕经济区许多城市不断崛起，但对周边甘 肃、宁夏等其他省份城市的辐射带动效果还不 够明显。

最后，从次冷点区和冷点区城市的空间分 布来看, 次冷点区主要分布在与次热点区城市 相邻的蒙甘宁地区少量城市之中。2005-2015 年, 次冷点区的面积逐渐扩大到甘肃西南部, 城市数量略有增加。而冷点区除分布在内蒙古 中东部的部分城市外, 主要分布在蒙甘宁三地 的西部。一般来说, 由于地理位置和自然环境 的原因, 次冷点区与冷点区城市的经济发展起 点较低，与热点区城市和次热点区城市的经济 交流与沟通比较有限, 也难以受到来自这些地 区的辐射和扩散，因而导致了市域经济发展一定程度的边缘化，经济发展的总体水平相 对落后。

从总体上看，晋陕蒙甘宁地区的市域经济发展逐渐出现了以西安、呼和浩特、太原 黄金三角地区为核心区，并且以山西、陕西和内蒙中部为腹地，向西部与东北部逐步呈 现梯度弱化的基本模式与格局。实际上，这个地区是中国重要的能源化工基地和能源战 略延续基地，因此工业发展潜力巨大。上述发展模式的形成，也将在一定程度上为“一 
带一路” 倡议的实施和西部地区的快速发展提 供动力保障。从热点区和次热点区的格局演变 来看, 黄金三角的发展格局正在不断强化, 导 致甘肃、宁夏和内蒙古西部地区出现了较为明 显的冷点化趋势, 这清楚地表明其所受到的辐 射带动驱动作用有一定的减弱趋势并出现了某 种虹吸效应，因此值得警惕。

\subsection{5 耦合协调度空间格局演化特征}

根据耦合协调度的计算方法，结合熵权 TOPSIS 方法, 可以计算出晋陕蒙甘宁地区 2000 年、2010年、2015 年各城市的耦合协调 度, 然后利用 ArcGIS 10.2 将耦合协调度进行 空间可视化展示, 结果见图 4。可以看出, 2000-2015 年间 47 个城市总体上处于低耦合协 调状态。其中, 各城市在 2000 年的平均耦合 协调度仅为 $0.107,2010$ 年各城市平均耦合协 调度降至 $0.106,2015$ 年各城市平均耦合协调 度又进一步下降到 0.105 的水平，同时各城市 的耦合协调度分布情况略有变化。从 47 个城 市耦合协调度的空间分布来看，处于晋陕蒙甘 宁西部区域的城市在耦合协调性方面显著低于 该区域的东部城市，这也与市域经济发展水平 的总体空间演化模式相一致。耦合协调度稍好 的城市仍主要集中在山西、陕西和内蒙古, 尤 其是三省的交界地区。总体而言，晋陕蒙甘宁 地区市域经济发展协调性不足的问题较为突 出, 这也主要与该地区经济发展相对薄弱, 经 济结构过于依赖能源和化工产业存在密不可分 的关系。该区域的大多数城市对经济规模、经 济效益、结构水平、人民生活和对外开放这些 反映市域经济发展的重要方面之间的耦合协调 性缺乏有效调控手段，致使其市域经济发展中 不平衡和不充分的问题较为突出。

\section{3 结论与讨论}

\section{1 结论}

本文运用熵权 TOPSIS 方法对晋陕蒙甘宁地区地级以上城市的市域经济发展水平进行 了综合评价，并运用马尔可夫转移概率分析方法和 ESDA 空间分析方法，对该区域内市 域经济发展水平时空分布差异格局的演化特征进行了探索。在此基础上，进一步采用耦 
合协调度测算方法探究该地区各城市的市域经济发展平衡与协调问题，具有一定的创新 性。研究结果表明：（1）晋陕蒙甘宁地区城市间的经济发展差距在波动中逐渐缩小，且 没有出现城市间经济发展水平差距持续拉大的趋势，表明该地区的市域经济并未朝着两 极化加剧的方向发展，市域经济差距在不断缩小，在实现协调发展方面具有一定基础。 这一发现的启示在于：如要实现该类地区市域经济的协调发展，必须对其差异水平与变 化趋势加以精确测度。而在类似的能源富集区发展中，市域经济往往很可能存在较为明 显的差异, 因此需要采取有效措施使其呈现不断收窄的趋势, 从而为协调发展创造良好 基础。（2）不同经济发展水平等级的城市在不同时期呈现出了截然相反的演化规律。随 着时间推移, 非低等级城市的等级下降风险更高。这一结果表明, 应当高度重视城市等 级突变的风险, 尤其对市域经济水平较好的城市, 应当思考提高其发展可持续性的有效 措施。启示在于：对类似于晋陕蒙甘宁地区的能源富集区来说，由于其经济发展往往较 为倚重以能源为代表的资源密集型产业, 市域经济往往存在产业结构单一, 抗风险能力 较弱的问题, 因此需要警惕其发展中可能出现的市域经济发展水平降级风险, 采取积极 有效措施提高其健壮性, 并增强其防范重大风险的能力。（3）2005-2010年，山西、陕 西、蒙南、宁夏市域经济发展水平存在一定程度的空间负相关关系，区域城市之间的良 性互动尚未形成, 2015 年这种关系不再显著。这一结果表明, 该地区市域经济发展已经 朝一体化方向有所改进，但仍然需要警惕其历史发展中曾经出现的过度同质化与缺乏有 效互动的问题。该发现的启示在于：对类似的能源富集区城市而言，其协同发展的关键 在于空间上的相互支撑，因此需要精确度量该类地区市域经济发展的空间关联属性，采 取有力措施防止发展的过度同构与非良性竞争。(4) 晋陕蒙甘宁地区的市域经济发展逐 渐出现了以西安、呼和浩特、太原为极核的黄金三角地区, 并且呈现出以山西、陕西和 内蒙古中部为腹地向西部和东北部逐步弱化的基本格局。然而，黄金三角的发展格局仍 在强化, 这导致出现了一些值得警惕的虹吸效应问题，致使甘肃、宁夏以及内蒙的西部 地区出现了明显的冷点化趋势。这一发现实际上为类似于晋陕蒙甘宁的能源富集区市域 经济发展敲响了警钟, 即在努力做强优势局部的同时, 应当使经济活动在城市间形成双 向有机循环, 而非单向运动, 需充分发挥城市群网对区域内各市域经济的整体带动作 用。（5）晋陕蒙甘宁地区城市的经济系统整体上处于低耦合协调状态，大多数城市处于 极端不平衡和严重不平衡状态, 市域经济发展中不平衡、不充分的问题较为突出。这一 结果事实上指出了影响该类能源富集区市域经济协调发展的关键性问题, 即如果将各城 市的经济发展看作是一个有机整体, 那么各城市内部的市域经济也应当是一个平衡协调 的系统, 其各子系统之间应当耦合协调发展。只有这样, 区域的整体协调发展才能得 以实现。

\section{2 讨论}

一方面，努力提高能源富集区在市域经济发展方面的可持续性与各子系统之间的协 调性。晋陕蒙甘宁地区属于能源富集区，该类地区的市域经济往往存在结构不合理的问 题, 一三产业占比过低, 二产业占比过高, 对能源产业依赖性较大是这类城市经济结构 的共性问题，往往致使该类地区的市域经济发展具有脆弱性，一旦面临冲击，产业间相 互支撑的作用较差, 经济发展的周期性较长。为了提高类似于晋陕蒙甘宁的能源富集区 市域经济发展可持续性, 应当着力提高城市产业发展的战略规划水平, 加强顶层设计并 建立产业风险预警机制, 积极利用国家的相关扶持政策, 想方设法延长原有产业链, 并 
结合所处区域周边较发达城市的特点与自身优势, 积极吸引非能源产业转移, 合理调整 自身产业结构，促使发展向着高质量化的方向提升。同时，还应着力改善城市宜居性， 增强城市基础设施建设水平, 加大对有助于城市经济转型升级的相关人才引进力度, 着 力构筑吸引相关高新技术人才的产业环境, 提高区域产业链的技术高度与深度, 为地方 经济打造新的活力增长点，从而实现经济活动与人才流动在能源富集区城市间的双向循 环流动。市域经济作为一个复合生态系统, 其各子系统之间在结构、功能等各方面均存 在耦合协调关系。随着晋陕蒙甘宁地区各城市经济发展水平的不断提升, 市域经济各子 系统之间的相互作用也在不断加强。因此应当努力调和矛盾，大力提高各子系统的发展 水平, 充分抓住新型城镇化、区域一体化、新旧动能转换与高质量发展等一系列战略机 遇, 实现市域经济发展、人民生活提升与对外开放扩大等目标的协调，以及实现经济规 模、效益与结构的平衡、充分发展。

另一方面，大力统筹区域协调发展并打破地区界限以实现地区间合理分工。对类似 于晋陕蒙甘宁的能源富集区而言，各城市在市域经济发展方面必须站在区域整体高度， 合理规划空间布局，优化产业结构，防止由于城市间的过度产业同构或同质发展带来恶 性竞争的问题，致使城市间差距不断加大。要积极促进产业向高质量化的方向发展，合 理规划产业布局，促进产业升级，就应当充分发挥各省区的资源优势，促进区域产业创 新能力的有效提升。同时，要实现能源富集区的经济协调一体化发展，就必须进一步提 高区域整体的对外开放程度与水平，逐步加强投资环境建设，实现地区经济的开放式发 展。为此, 尤其应加强对道路运输、供水、供电、通信等基础设施的投资, 建设吸引外 资的信息和物流基础设施。要实现开放式发展，就要求有关政府和行政部门进一步解放 思想，从发展与开放的角度与整个能源富集区的整体高度看待发展问题，实现区域内要 素的合理流动，推动区域协调发展。打造能源富集区的经济一体化与实现区域协调发展 是一项系统工程，必须从系统优化的角度保持建设目标的一致性。经济基础较好、环境 承载力较强、发展潜力较大的地区要实施重点发展, 充分发挥区域的主导作用。同时, 要着力培育周边城市的经济增长点, 努力发挥周边城市的地理优势, 深化区域分工与合 作，建立互动合作发展模式。

\section{参考文献(References):}

[1] 王保忠, 何炼成, 李忠民. 能源富集区构建环境行政协调机制创新研究: 以晋陕蒙宁省区为例. 延安大学学报: 社会 科学版, 2013, 35(5): 71-76. [WANG B Z, HE L C, LI Z M. Research on establishing innovative environmental administrative coordination mechanism in energy-rich areas: Taking Shanxi-Shaanxi-Meng-Ning province as an example. Journal of Yan'an University: Social Science Edition, 2013, 35(5): 71-76.]

[2] 夏四友, 文琦, 熊欢. 基于 DEA 的能源富集区经济发展效率实证研究: 以陕西省榆林市为例. 地域研究与开发, 2016, 35(5): 47-52. [XIA S Y, WEN Q, XIONG H. Comprehensive evaluation on efficiency of economic development in resource-rich area: A case study of Yulin city in Shaanxi province. Areal Research and Development, 2016, 35(5): 47-52.]

[3] 张宇, 曹卫东, 梁双波, 等. 中部地区资源型城市质量与规模时空差异演化研究: 以山西省为例. 自然资源学报, 2018, 33(2): 233-245. [ZHANG Y, CAO W D, LIANG S B, et al. Research on spatial and temporal evolution of quality and scale of resource based cities in central region of China: A case study of Shanxi province. Journal of Natural Resources, 2018, 33(2): 233-245.]

[4] 王安. 合理开发煤炭资源从战略上保证我国能源安全: 对加快晋陕蒙宁煤炭战略基地建设的思考. 宏观经济研究, 2009, (3): 3-8, 18. [WANG A. Rational development of coal resources, strategically guaranteeing China's energy security: Reflections on accelerating the construction of Jin-Shan-Meng-Ning Coal Strategic Base. Macroeconomics, 2009, (3): $3-8,18$.

[5] 薛静静, 沈镭, 彭保发, 等. 中国能源生产和消费大省的能源供给安全综合评价及优化: 以陕西省和广东省为例. 自 然资源学报, 2015, 30(10): 1686-1697. [XUE J J, SHEN L, PENG B F, et al. Assessment and optimization on energy 
supply security of high energy producing and high energy consumption provinces in China: Cases study of Shaanxi and Guangdong provinces. Journal of Natural Resources, 2015, 30(10): 1686-1697.]

[6] 李星, 马永祥, 贾明霞, 等. 甘肃产业布局供给侧改革研究: 以“一带一路” 的视角. 宏观经济管理, 2017, (s1): 310311. [LI X, MA Y X, JIA M X, et al. Research on supply side reform of Gansu industrial layout: From the perspective of "The Belt and Road". Macroeconomic Management, 2017, (s1): 310-311.]

[7] 王海飞, 孔维新, 蔡定昆. 国内外资源型城市发展对甘肃资源型城市的启示: 兼论庆阳城市发展战略. 甘肃社会科 学, 2013, (3): 207-210. [WANG H F, KONG W X, CAI D K. The enlightenment of the development of resource-based cities at home and abroad to resource-based cities in Gansu: On the development strategy of Qingyang city. Gansu Social Sciences, 2013, (3): 207-210.]

[8] 石敏俊, 黄文, 李娜. 资源优势能否转化为产业优势: 煤炭开发重心西移对能源密集型产业空间格局变化的影响. 自 然资源学报, 2015, 30(6): 891-902. [SHI M J, HUANG W, LI N. Can resource advantage become industrial advantage: Impact of the westward shift of coal production on the spatial pattern of energy intensive industries in China. Journal of Natural Resources, 2015, 30(6): 891-902.]

[9] 张进海, 刘天明, 李文庆, 等. 银鄂榆三角区域经济发展战略研究. 宁夏社会科学, 2010, (6): 22-26. [ZHANG J H, LIU T M, LI W Q, et al. Research on the economic development strategy of the region of Yin-E-Yu. Social Sciences in Ningxia, 2010, (6): 22-26.]

[10] 项㴋智, 贾绍凤. 中国能源产业的现状需水估算与趋势分析. 自然资源学报, 2016, 31(1): 114-123. [XIANG X Z, JIA S F. Estimation and trend analysis of water demand of energy industry in China. Journal of Natural Resources, 2016, 31(1): 114-123.]

[11] 沈镭, 张红丽, 钟帅, 等. 新时代下中国自然资源安全的战略思考. 自然资源学报, 2018, 33(5): 721-734. [SHEN L, ZHANG H L, ZHONG S, et al. Strategic thinking on the security of natural resources of China in the New Era. Journal of Natural Resources, 2018, 33(5): 721-734.]

[12] 俞海山, 林崇建. 市域经济理论与实践研究. 北京: 经济科学出版社, 2009. [YU H S, LIN C J. Research on Theory and Practice of Municipal Economy. Beijing: Economic Science Press, 2009.]

[13] 赵永, 王劲峰. 中国市域经济发展差异的空间分析. 经济地理, 2007, 27(3): 357-361. [ZHAO Y, WANG J F. Spatial analysis of city-wide economic development in China. Economic Geography, 2007, 27(3): 357-361.]

[14] 李航飞, 韦素琼, 陈松林. 海峡西岸经济区市域经济网络结构及成因分析. 经济地理, 2017, 37(7): 63-70, 78. [LI H F, WEI S Q, CHEN S L. An analysis on the network structure and formation causes of regional economic connection in the west coast of Taiwan Straits Economic Zone. Economic Geography, 2017, 37(7): 63-70, 78.]

[15] 李锦峰. 构建晋陕蒙宁区域经济一体化的路径选择. 理论导刊, 2012, (4): 75-76. [LI J F. The path choice of constructing regional economic integration of Jin-Shan-Meng-Ning area. Journal of Socialist Theory Guide, 2012, (4): 75-76.]

[16] 安树伟, 间程莉. 山西经济发展的功能定位与战略思路. 经济问题, 2017, (10): 1-7. [AN S W, YAN C L. Functional positioning and strategic thinking of Shanxi's economic development. On Economic Problems, 2017, (10): 1-7.]

[17] 郝渊晓. 构建现代供应链体系培育陕西经济新动能. 西部大开发, 2018, (4): 51-52. [HAO Y X. Constructing a modern supply chain system, cultivating Shaanxi's new economic momentum. West China Development, 2018, (4): 51-52.]

[18] 柴国君, 李丹. 影响内蒙古经济增长质量的因素分析. 经济论坛, 2014, (1): 46-49. [CHAI G J, LI D. Analysis of factors affecting the quality of Inner Mongolia economic growth. Economic Forum, 2014, (1): 46-49.]

[19] 姚春玲. 社会环境因素对内蒙古经济发展的影响研究. 经济研究导刊, 2012, (5): 44-45. [YAO C L. Research on the influence of social environment factors on Inner Mongolia economic development. Economic Research Guide, 2012, (5): 44-45.]

[20] 孟士翔. 人口老龄化对经济发展的影响研究: 以内蒙古自治区为例. 内蒙古科技与经济, 2011, (14): 17-18. [MENG S X. Study on the influence of population aging on economic development: Taking Inner Mongolia Autonomous Region as an example. Inner Mongolia Science Technology \& Economy, 2011, (14): 17-18.]

[21] 李东霖, 李悦榕. 甘肃经济发展的现状与战略路径. 当代经济, 2013, (3): 80-82. [LI D L, LI Y R. The status quo and strategic path of Gansu economic development. Contemporary Economics, 2013, (3): 80-82.]

[22] 曹颖轶. 宁夏经济空间结构演变及特点. 干旱区资源与环境, 2010, 24(7): 10-14. [CAO Y Y. Evolution and characteristics of spatial economic structure in Ningxia province. Journal of Arid Land Resources and Environment, 2010, 24(7): 10-14.]

[23] HWANG C L, YOON K. Multiple Attribute Decision Making. New York: Springer-Verlag, 1981.

[24] 程钰, 任建兰, 崔昊, 等. 基于熵权 TOPSIS 法和三维结构下的区域发展模式: 以山东省为例. 经济地理, 2012, 32(6): 27-31. [CHENG Y, REN J L, CUI H, et al. A research using entropy-TOPSIS method on regional development modes in 
perspective of the three-dimensional framework: A case study of Shandong province. Economic Geography, 2012, 32 (6): 27-31.]

[25] 曹贤忠, 曾刚. 基于熵权 TOPSIS 法的经济技术开发区产业转型升级模式选择研究: 以芜湖市为例. 经济地理, 2014, 34(4): 13-18. [CAO X Z, ZENG G. The mode of transformation and upgrading based on the methods of entropy weight and TOPSIS in case of Wuhu Economic and Technological Development Zone. Economic Geography, 2014, 34(4): 13-18.]

[26] 邹秀清, 田娜. 中国土地财政的区域差异与演进过程: 基于 287 个地级市的面板数据. 资源科学, 2015, 37(11): 21622171. [ZOU X Q, TIAN N. Regional disparities and the evolution of China's land finance based on panel data for 287 prefecture-level cities. Resources Science, 2015, 37(11): 2162-2171.]

[27] ANSELIN L, SYABRI I, KHO Y, et al. GeoDa: An introduction to spatial data analysis. Geographical Analysis, 2006,38 (1): 5-22.

[28] 赵文亮, 陈文峰, 孟德友. 中原经济区经济发展水平综合评价及时空格局演变. 经济地理, 2011, 31(10): 1585-1591. [ZHAO W L, CHEN W F, MENG D Y. The comprehensive evaluation of the economic development level of the Central Plains Economic Zone. Economic Geography, 2011, 31(10): 1585-1591.]

[29] 赵明华, 郑元文. 近 10 年来山东省区域经济发展差异时空演变及驱动力分析. 经济地理, 2013, 33(1): 79-85. [ZHAO M H, ZHENG Y W. Spatial and temporal evolution and driving forces of regional economic development disparity in Shandong province in recent 10 years. Economic Geography, 2013, 33(1): 79-85.]

[30] 孟德友, 李小建, 陆玉麒, 等. 长江三角洲地区城市经济发展水平空间格局演变. 经济地理, 2014, 34(2): 50-57. [MENG D Y, LI X J, LU Y Q, et al. The spatial pattern evolution of urban economic development level in the Yangtze River Delta. Economic Geography, 2014, 34(2): 50-57.]

[31] ILLING W V. The Penguin Dictionary of Physics. Beijing: Beijing Foreign Language Press, 1996.

[32] 梁威, 刘满凤. 战略性新兴产业与区域经济耦合协调发展研究: 以江西省为例. 华东经济管理, 2016, 30(5): 14-19. [LIANG W, LIU M F. A study on the coupling and coordinated development of strategic emerging industries and regional economy: Evidence from Jiangxi province. East China Economic Management, 2016, 30(5): 14-19.]

[33] 刘松, 楼嘉军. 2003-2013 年中国城市休闲化质量评估: 耦合与协调双重视角的考察. 软科学, 2017, 31(2): 87-91. [LIU S, LOU J J. Quality assessment of urban leisure in China from 2003 to 2013: An investigation from the dual perspectives of coupling and coordination. Soft Science, 2017, 31(2): 87-91.]

[34] 郝生宾, 于渤. 企业技术能力与技术管理能力的耦合度模型及其应用研究. 预测, 2008, 27(6): 14-15. [HAO S B, YU B. Research on coupling degree model and application of the enterprise's technology capacity and technology management capacity. Forecasting, 2008, 27(6): 4-15.]

[35] 廖重斌. 环境与经济协调发展的定量评判及其分类体系: 以珠江三角洲城市群为例. 热带地理, 1999, 19(2): 76-82. [LIAO C B. Quantitative evaluation of environmental and economic coordinated development and its classification system: A case study of the Pearl River Delta Urban Agglomeration. Tropical Geography, 1999, 19(2): 76-82.]

[36] 陈培阳, 朱喜钢. 中国区域经济趋同: 基于县级尺度的空间马尔可夫链分析. 地理科学, 2013, 33(11): 1302-1308. [CHEN P Y, ZHU X G. Regional convergence at county level in China. Scientia Geographica Sinica, 2013, 33(11): 1302-1308.]

[37] 周晓艳, 郝慧迪, 叶信岳, 等. 黄河流域区域经济差异的时空动态分析. 人文地理, 2016, 31(5): 119-125. [ZHOU X Y, HAO H D, YE X Y, et al. A spatial-temporal analysis of regional economic inequality in Yellow River Valley. Human Geography, 2016, 31(5): 119-125.] 


\title{
Spatial pattern evolution of municipal economic development in energy-rich areas:
} A case study of Shanxi-Shaanxi-Inner Mongolia-Gansu-Ningxia region

\author{
LI Bo ${ }^{1,2}$, ZHANG Wen-zhong ${ }^{2,3}$, YU Jian-hui ${ }^{2,3}$, LIU Qian-qian ${ }^{4,5}$ \\ (1. School of Management, Tianjin University of Technology, Tianjin 300384, China; 2. Key Laboratory of \\ Regional Sustainable Development Modeling, Institute of Geographic Sciences and Natural Resources \\ Research, CAS, Beijing 100101, China; 3. University of Chinese Academy of Sciences, Beijing 100049, China; \\ 4. School of Geography Science, Nanjing Normal University, Nanjing 210023, China; \\ 5. Jiangsu Center for Collaborative Innovation in Geographical Information Resource Development and \\ Application, Nanjing 210023, China)
}

\begin{abstract}
This paper uses the entropy-weighted TOPSIS method to comprehensively evaluate the municipal economic development of prefecture-level cities in the Shanxi-Shaanxi-Inner Mongolia-Gansu-Ningxia (SSIGN) region. Then, it explores the spatio-temporal differentiation of economic development of the region using Markov transition probability analysis method and ESDA spatial analysis method. The results show that: (1) From 2005 to 2015, the gap in municipal economic development between cities in the SSIGN region was narrowed in the fluctuations, indicating that the municipal economic of the study region had not developed towards polarization, and there was a certain foundation for achieving coordinated development. (2) Each economic development grade city presented a diametrically opposite evolution law in different periods. Over time, all besides the lowest-grade cities had a higher risk of grade decline. This result indicates that for cities with higher municipal economic level, effective measures shoud be taken to improve their economic development sustainability. (3) From 2005 to 2010, to a certain degree, there was a significant spatial negative correlation between the economic levels of the cities in the SSIGN region. A positive interaction needs to be formed in this region. By 2015, this relationship was no longer significant. This result indicates that the municipal economic development of the region has improved in the direction of positive integration, but we still need to be alert to the problems of excessive homogenization and lack of effective interaction that have occurred in the historical development of this region. (4) The regional economic development of the SSIGN region has gradually emerged in the spatial pattern of the Golden Triangle consisting of Xi'an, Hohhot and Taiyuan. However, there has also been a clear cold spot in the study region. (5) The municipal economic development system in the cities of this region is generally in a state of low coupling coordination, and unbalanced economic development and uncoordinated are prominent. This result actually points out the key issue affecting the overall coordinated development of the region's economy. That is, the economic development subsystems within the city should also be a balanced system and coordinated development should be achieved among these subsystems.
\end{abstract}

Keywords: Shanxi-Shaanxi-Inner Mongolia-Gansu-Ningxia region; municipal economy; economic development level; entropy weight TOPSIS; ESDA 